\title{
Through the Looking Glass: A Literature Review of a Rare Pediatric Neuropsychiatric Condition: Alice in Wonderland (Todd's) Syndrome
}

\author{
Brittany Harrison, $\mathrm{HBSc}^{1}$, Adrienne Harrison, $\mathrm{HBSc}^{2}$ \\ ${ }^{1}$ Faculty of Medicine, University of Ottawa \\ ${ }^{2}$ Department of Psychology, Neuroscience \& Behaviour, McMaster University
}

A B S T R A C T

Alice in Wonderland Syndrome (AIWS), a.k.a Todd's Syndrome, is a neuropsychiatric disorder characterized by a collection of rare, visually distortive symptoms such as micropsia, telopsia, macropsia, metamorphosia, pelospia, impaired passage of time and zooming of the environment. This article aims to review and organize the relevant articles written on AIWS, including a summary of the original research on etiology, imaging, comorbidities and treatments of AIWS, as well as historical accounts of cases from the 1950s, when it was first described. The articles included in this review were collected via the databases PubMed, SCOPUS and MedLine; a total of 18 articles were reviewed. Articles that were not in English were omitted from this review. Articles were not restricted by date of publication, as the goal was to incorporate the historical references of AIWS. In summary, AIWS is mainly a pediatric phenomenon, though there have been cases of comorbidity with depression and Lyme disease in adults. The syndrome is seen to be associated with infection, trauma, and migraine headaches. Imaging studies have discovered areas of hypo-perfusion in certain areas of the brain during episodes of AIWS; these areas mainly include the occipital lobe, but there are reports of frontal and temporal hypo-perfusion as well. This is a rare and interesting neuropsychiatric syndrome that presents with unique visual hallucinations. In the pediatric population, it may be a sign of undiagnosed viral infection that warrants further testing.

\section{RÉSUMÉ}

Le Syndrome d'Alice au pays des merveilles (AIWS), aussi connu sous le nom de Syndrome de Todd, est un trouble neuropsychiatrique caractérisé par une multitude de symptômes rares, de distorsion visuelle tels que la micropsie, telopsie, macropsie, metamorphosie, pelospie, troubles de passage du temps et le zoom de l'environnement. Cet article vise à examiner et organiser les articles pertinents écrits sur AIWS, y compris un résumé de la recherche originale sur l'étiologie, l'imagerie, les comorbidités et les traitements d'AIWS, ainsi que les comptes historiques de cas à partir des années 1950, quand le syndrome a été décrit pour la première fois. Les articles inclus dans cette étude ont été assemblés via les bases de données PubMed, SCOPUS et MedLine ; un total de 18 articles a été examiné. Les articles non-rédigés en anglais ont été omis de cette revue. Les articles n'ont pas été limités par date de publication, car l'objectif était d'incorporer les références historiques d'AIWS. En résumé, AIWS est un phénomène essentiellement pédiatrique, bien qu'il y ait eu des cas de comorbidité avec la dépression et la maladie de Lyme chez les adultes. Le syndrome est associé à des infections, traumatismes, et migraines. Les études d'imagerie ont découvert des zones d'hypo-perfusion dans certaines parties du cerveau pendant les épisodes d'AIWS ; ces zones comprennent principalement le lobe occipital, mais il existe aussi des rapports d'hypo-perfusion frontale et temporale. Ceci est un syndrome neuropsychiatrique rare et intéressant qui présente avec des hallucinations visuelles uniques. Dans la population pédiatrique, il peut être un signe d’infection virale non diagnostiquée qui justifie des tests supplémentaires.

\section{INTRODUCTION, HISTORY \& SYMPTOMOLOGY}

Alice in Wonderland Syndrome (AIWS), a.k.a Todd's Syndrome, is a neuropsychiatric disorder that manifests with debilitating visually distortive symptoms. In 1955, the British psychiatrist Dr. John Todd recognized a small group of his migraine patients describing objects' size as out of proportion to the environment. He later named the disease after Lewis Caroll's literary character, Alice in Wonderland, who suffered similar distortive hallucinations $[15,16]$.
An episode of AIWS may include any number of the following symptoms: micropsia and macropsia, which is when objects are perceived as smaller or larger than they are in reality; telopsia and pelopsia, which is when a stationary object appears further or closer than it is in reality; metamorphosia, which is when straight lines on objects appear distorted; and impaired passage of time and zooming of the environment, which is somewhat similar to vertigo [1-5]. While micropsia and telopsia are the most common symptoms [5], AIWS may also include subjective feelings such as

Keywords: Todd's Syndrome; Alice in Wonderland Syndrome; Hallucinations 
derealization, somatopsychic duality, altered sense of touch and illusory alterations of the passage of time [1]. The average age of onset is between 5-10 years of age, although there have been case reports of comorbidity with depression and adult onset episodes $[2,6]$. This unusual neuropsychiatric picture can often be confused with psychosis or drug intoxication [4].

\section{BURDEN TO PATIENTS}

There are a few online forums and support groups, like aiws.info, for sufferers of AIWS. Here, patients express feelings about how AIWS affects their daily lives. Patients who experience daily spells have a high disease burden and have noted a number of troublesome symptoms that severely affect their lives, such as: "seeing the world through a fish-eye lens is very difficult"; "I'm unable to judge distances accurately"; "I would often move clumsily or overcompensate". "Crossing the road feels dangerous, walking in a straight line is tricky, I run into door frames"; "sometimes it's impossible to tell if my window is just $1 \mathrm{~mm}$ high, or a huge window miles away" [7]. Many patients have to alter their lives to work from home, and some have started to avoid socializing all together. When the frequency and duration of episodes starts to affect functioning, AIWS can be quite a debilitating disorder.

\section{PROGNOSIS}

In paediatrics, many of these cases resolve fully, but a number of patients can suffer with the syndrome for their entire lives [8]. In one retrospective chart review study of 48 patients, followup revealed that of all diagnosed patients with AIWS, $40 \%$ had no further AIWS events, $40 \%$ had continued to experience perceptual distortions, and $20 \%$ had more than one episode after diagnosis, but had been symptom-free for at least 6 months. The average interval between diagnosis and telephone contact by the research team was 6.5 years. In addition, $27 \%$ subsequently developed migraines, and one rare case had developed a seizure disorder [5]. This study also revealed that family history is present in $33 \%$ of patients [5].

\section{ETIOLOGY}

The average age of onset for AIWS was shown by one study $(n=48)$ to be 8.1 years [9]. The etiology of AIWS is infection in $33 \%$ of cases, while head trauma and migraine each account for $6 \%$ of cases [9]. The remainder of cases did not have an identifiable cause [3, 9-10]. In various studies, Epstein Barr virus, and other febrile viral infections, such as varicella, coxsackievirus B1, and $\mathrm{H} 1 \mathrm{~N} 1$, have been implicated along with complex partial epilepsy $[6,8,11]$. The trigger of each case of AIWS is determined to be migraine when the patient's visual complaints occur in association with a headache, seizure if the visual complaints have an electroencephalogram (EEG) correlate on random or ambulatory monitoring, and infection if the visual complaint occurred within days of febrile illness [5]. Numerous studies have concluded that any young child presenting with AIWS should undergo examination for Epstein-Barr virus infection [9].

As well as the above listed etiologies, recent studies have demonstrated a link between AIWS and Lyme disease. A case report of a healthy 7-year-old boy showed 3 events of distorted perception, specifically a feeling of himself becoming smaller. He expressed that book print appeared further away. During a 36-hour EEG recording, none of these events displayed seizure activity, nor were these events accompanied by abnormal motor activity [11]. Lyme disease Western blot immunoglobulin M on day 10 of the illness tested positive in both serum and cerebrospinal fluid of this patient [11]. It has therefore been suggested that Lyme disease should be added to the clinical spectrum of people presenting with AIWS with an unknown cause [11].

In the adult world, depressive psychiatric illness is more commonly the cause of AIWS [6]. There have been cases of admitted psychiatric patients with diagnoses of major depressive episodes developing macropsia and metamorphosia; in these cases, both the depression and the AIWS were cured with 10 cycles of electroconvulsive therapy, with no signs of relapse [6].

\section{PATHOPHYSIOLOGY}

Though no precise pathophysiologic process has been determined, there have been a number of hypotheses; the majority believe that cerebral perfusion or edema is the mechanism that causes neuronal compromise. Studies of cerebral perfusion note that patients have decreased perfusion near the visual tract and visual cortex [9]. Another projection is that focal hypo-perfusion resulting in ischemia can alter central neurotransmitter efficacy [13]. Others believe that an acute inflammation in the brain parenchyma in conjunction with increases or decreases in perfusion can manifest with the clinical symptoms [14]. There is no clear consensus on the exact mechanism for this constellation of symptoms. It is likely different in each individual patient.

\section{NEUROIMAGING}

Since the initial publication in 1955, advances in medical technology have been made, allowing neuroimaging techniques to capture a number of episodes of AIWS. Imaging of the brain during episodes of AIWS has been predominantly in pediatric cases related to Epstein-Barr virus. Structural abnormalities can rarely be linked to AIWS when assessed by computed-tomography (CT) and magnetic resonance imaging (MRI) [1, 12], as the likely pathophysiology is due to a perfusion issue, which cannot be demonstrated by these two imaging modalities unless enhanced with contrast to more clearly demonstrate vascular changes. However, one study published in Japan has reported an abnormal MRI finding during an episode of AIWS. The MRI demonstrated "transient T2 prolongation and swelling of the cerebral cortex, especially at the bilateral temporal lobes, bilateral cin- 
gulate gyrus, right upper frontal gyrus, bilateral caudate nucleus and bilateral putamen" [12]. Electroencephalography (EEG) and single-photon emission computed tomography (SPECT) scanning yield more useful results when trying to pinpoint the functional origin of these episodes because these scans can demonstrate dynamic changes. EEG can show only electrophysiologically abnormal lesions, while SPECT scan methods can portray perfusion and metabolism [7].

\section{EEG}

In a number of pediatric cases, aged 10-16, episodes of visual hallucinations (specifically micropsia) show changes at the parieto-occipital and occipital EEG electrodes $[3,10]$. These changes demonstrated "normal background alpha rhythms with a few generalized series of sharp, high voltage waves in the parieto-occipital region" $[3,10]$. Others showed "some overall slowing and irregularity of background activity in the occipital region" [13]. Overall, EEG has demonstrated non-specific signalling abnormalities when capturing an episode of AIWS. The occipital regions are often affected, but, to this date, an exact pathway has not been determined. Many of the EEG studies were followed up with MRI, CT or SPECT scanning studies.

\section{SPECT SCANNING}

Blood perfusion of brain tissue using SPECT scanning has reported hypo-perfusion in various areas of the brain. The right parietal and occipital cortices were affected in 9 of 13 cases in one study. In the same study, none of the 13 cases demonstrated left parietal hypo-perfusion [2]. Others have reported hypo-perfusion in the right frontal and right frontotemporal regions [14], and decreased cerebral perfusion near the visual tract and visual cortex in the studied patients [18].

It has been concluded that in most patients with AIWS, the EEG, $\mathrm{CT}$ and MRI are unable to determine any precise pathological areas [14]. However, neuroscientists are confident that structural lesions are not the cause of these hallucinations. It is a functional, hypo-perfused, lesion that contributes to the constellation of symptoms [3,18-19].

\section{TREATMENT}

Treatment of AIWS is largely dependent on the etiology. If a viral infection is manifesting itself within days of the hallucinations, symptomatic treatment is the only indicated therapy but may not resolve the symptoms [5]. When epilepsy is the cause, AIWS hallucinations resolve with treatment of the seizure [5]. In children who have primary AIWS, without an infectious trigger, repetitive transcranial magnetic stimulation (rTMS) at a frequency of $1 \mathrm{~Hz}$ overlying Brodmann's area 40 was the prescribed treatment. In this case report, metamorphosia symptoms completely regressed for 8 months [20]. The authors of this article believe rTMS should be further investigated as a treatment option for AIWS.

\section{DISCUSSION AND CONCLUSION}

AIWS is a clinical entity that has been documented to be related to a number of etiologies. Migraine was the initial associated disorder, but with the development of new testing techniques and diagnoses, a number of infectious (varicella, Coxsackievirus, H1N1, and EBV), traumatic, and psychiatric (depression) causes have been found to be associated. AIWS is mainly a pediatric phenomenon, though there have been cases of comorbidity with depression in adults. Relatively new imaging studies have discovered areas of hypo-perfusion in various areas of the brain during episodes of AIWS; these affected areas are mainly occipital, but there are reports of frontal and temporal hypo-perfusion as well. Judging by the number of associated conditions, some neuroscientists believe that there may be a common neurotransmitter implicated in many of the cases, so further research may be needed to pinpoint its exact mechanism of action. As many as $40 \%$ of initial presentations will relapse throughout the lifetime of AIWS sufferers, so further investigations into pathophysiology may lead to treatment options for these patients. This article should help bring to light the lack of controlled research for this disorder, and the need for further research in the future.

This is a rare and interesting neuropsychiatric syndrome that presents with unique visual hallucinations. In the pediatric population, it may be a sign of undiagnosed viral infection that warrants further testing. Given that it affects mainly children, and that it is comorbid with diseases like Lyme disease, more awareness of AIWS and therefore earlier diagnosis could have an impact on the wellness of patients affected. Parents might take comments of distortion and discomfort from young children as part of an "active imagination", but it could indicate more serious neurological issues.

\section{REFERENCES}

1. Blom JD. A Dictionary of Hallucinations. New York: Springer; 2009. 14 p.

2. Brumm K, Walenski M, Love T. Functional MRI of a child with Alice in Wonderland syndrome during an episode of micropsia. J AAPOS. 2010;14(4):31722.

3. Bui E, Chatagner A, Schmitt L. Alice in Wonderland syndrome in major depressive disorder. J Neurophychiatry Clin Neurosci. 2010;22(1):352-3.

4. Cau C. Alice in Wonderland syndrome. Minerva Med. 1999 Oct;90(10):397401.

5. Liu A, Liu J, Liu G, Liu G. "Alice in Wonderland" syndrome: presenting and follow-up characteristics. Pediatr Neurol. 2014;51(3):317-20

6. Mizuno M, Kashima H, Chiba H, Murakami M, Asai M. "Alice in Wonderland" syndrome as a precursor to depressive disorder. Psychopathology. 1998;31(2): 85-9.

7. "Alice in Wonderland Syndrome". [Internet]. 2015 Apr 15 [cited 2015 Apr 20] Available at: www.aiws.org.

8. Stefano S, Faggioli R, Scarpa P, Borgna-Pignatti C. "Alice in Wonderland syndrome" and varicella. Pediatr Infect Dis J. 1998;17(10):935-6.

9. Liaw $\mathrm{S}$, Shen E. Alice in Wonderland syndrome as a presenting symptom of EBV infection. Pediatr Neurol. 1991;7(6):464-6.

10. Kuo Y, Chiu N, Shen E, Ho C, Wu M. Cerebral perfusion in children with Alice in Wonderland syndrome. Pediatr Neurol. 1998;19(2):105-8.

11. Millichap G. Alice in Wonderland syndrome and Lyme disease. AAP Grand Rounds. 2012;28(1):12. 


\section{Review and Clinical Practice}

12. Sasaki M, Kamei A, Chida S. Abnormal magnetic resonance imaging in a child with Alice in Wonderland syndrome following Epstein-Barr virus infection. No To Hattatsu. Brain and Development. 2002;34(4):348-52.

13. Lahat E, Berkovitch $M$, Barr J, Paret $G$, Barzilai A. Abnormal visual evoked potentials in children with "Alice in Wonderland syndrome" due to infectious mononucleosis. J Child Neurol. 1999;14(1):732-5.

14. Gencoglu E, Alehan F, Erol I, Koyuncu A, Aras M. Brain SPECT findings in patient with Alice in Wonderland syndrome. Clin Nucl Med. 2005;30(1):758-9.

15. Todd J. The syndrome of Alice in Wonderland. Can Med Assoc J. 1955;73:7014.

16. Lippman C. Certain hallucinations peculiar to migraine. J Nerv Ment Dis. 1952;116(4):346-51.

17. Cinbis $\mathrm{M}$, Aysun $\mathrm{S}$. Alice in Wonderland syndrome as an initial manifestation of Epstein-Barr virus infection. Br J Ophthamol. 1992;76(5): 316

18. Kitchener N. Alice in Wonderland syndrome. Int J Ch Neuropsychiatry. 2004;1(1):107-12.

19. Binalsheikh IM, Griesemer D, Wang S, Alvarez-Altalef R. Lyme neuroborreliosis presenting as Alice in Wonderland syndrome. Pediatr Neurol. 2012;46(3):185-6.

20. Blom, J., Looijestijn, J., Goekoop, R., Diederen, K., Rijkaart, A., Slotema, A. \& Commer, I. Treatment of Alice in Wonderland Syndrome and Verbal Auditory Hallucinations Using Repetitive Transcranial Magnetic Stimulation: A Case Report with fMRI Findings. Psychopathology. 2011; 44(1):337-44. 